\title{
The time has come to engineer tissues and not just tissue engineer
}

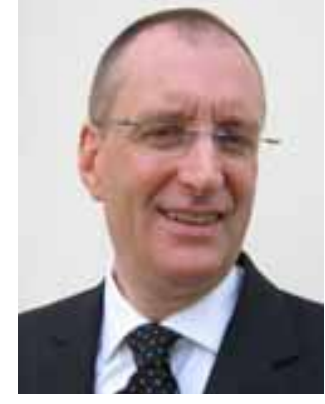

ChrisMasan

University College L ondon, Stem Cell and Regenerative M edicine Bioprocessing U nit, Advanced Centre for Biochemical Engineering, Roberts Building, Torrington Place, London WC1E 7JE, UK Tel.: +44 207679 0140; Fax: + 442072090703 E-mail: chrismason@ ucl.ac.uk
True regenerative medicine has many components including cell therapy and tissue engineering. However, all are linked by one common theme - to deliver safe, effective and consistent therapies to patients whose lives are dominated by chronic illness or life-threatening conditions for which there are currently no cures. This editorial highlights issues facing the successful translation and delivery of regenerative medicine products, using examples from the field of tissue engineering, as they travel the route from low volume specialist products to high volume routine clinical practice therapies.

Currently multiple approaches exist for the treatment of tissue or organ failure, for example, diabetic patients can be treated by dietary advice, tablets or injections. N one of these options however cures the patient, they just manage the disease by reducing its symptoms or progression. Thus despite insulin and all the other diabetic medications currently available, diabetes is still a leading cause of mortality and disability in the USA, accounting for nearly a quarter of a million deaths in 2002 [1]. This unfortunate situation is true for most chronic diseases, however, a potentially superior option is to grow replacement organs or tissues in the laboratory, better known as tissue engineering. Tissue engineering is the regeneration of biological tissues through the use of cells, with the aid of supporting structures and, sometimes, activating biomolecules [2]. The tissue-engineering sector is currently emerging as a multidisciplinary field demanding the integration of the life sciences, chemistry, engineering, clinical medicine and commerce, which in time is likely to have a major commercial impact.

From its origins in the early 1990s, the new and exciting tissue-engineering industry grew at an ever accelerating pace. By the start of 2001, there were nearly 2000 scientists and support staff spread over 34 companies with an annual spend of approximately $\$ 360 \mathrm{M}$ [3]. This phase was followed by a period of even more rapid decline, which by the start of 2003 left the industry back at its 1997 level [4,5]. D uring this turbulent time, the market leaders, O rganogenesis, Inc. (C anton, M A, USA) and Advanced Tissue Sciences, Inc. (La Jolla, CA, USA) filed voluntary petitions for reorganization under Chapter 11 of the U S Bankruptcy Code. M ost of the other companies in the sector either went out of business or considerably downsized [4]. Today there remain only two FD A fully approved tissue engineered products; A pligraf ${ }^{\mathrm{TM}}$ (O rganogenesis) and D ermagraft ${ }^{T M} *$ (Smith $\&$ Nephew formerly Advanced Tissue Sciences [*see acknowledgements]) with total combined sales in the order of $\$ 50 \mathrm{M}$ per annum despite several billions of dollars of investment $[6,7]$. However many medical products have had a history of early poor results followed by major success as they underwent the essential transition from $R \& D$ to product-based enterprises e.g., modern pharmaceuticals (1945-1955), controlledrelease drug delivery (1970-1980) and monoclonal antibodies (1985-2000) [8]. Engineered 3D human tissues is even more complex than any of these nonliving materials.

The long-term aim of tissue engineering is to facilitate the routine medical replacement of failing organs, everything from skin to hearts. The established general principles of tissue engineering involve starting with a cell-friendly polymer, shaping it into the desired geometry to form a 3D scaffold, seeding the scaffold with living cells and then growing it in tissue culture medium within an environmentally controlled bioreactor. As the cells multiply they populate the scaffold and synthesize extracellular matrix to create a 3D tissue. All the FDA-approved tissueengineered products have been skin substitutes and all were made using low volume 'cottage industry' techniques. Such low volume techniques are of course essential at the start of any industry - even $\mathrm{H}$ enry Ford started out building single cars in a shed behind his home in $D$ etroit before pragmatically moving 
onto factory fabrication, automation, assembly lines and mass production in order to expand the business and provide 'cars for the masses'. Tissue engineered products are no different; today low volume is acceptable; however, for the industry to truly thrive, production must be efficiently scalable. Part of the reason behind the current low volume approach can also be attributed to the origins of the industry. The first generation of products came directly from academia and thus did not have the necessary commercial rigour incorporated into their initial $R \& D$ stage, e.g., overall design strategy, preclinical/clinical trials and FDA approval planning, quality control and scalable economic manufacture, marketing, distribution and reimbursement strategies [9]. Thus research, development and translation need ide ally to proceed in parallel if a tissue-engineering product is to realize its true potential. W ithout effective manufacturing from the outset, later modification to the manufacturing process may come at a very high price, for example, the requirement for regulatory reapproval or even additional clinical trials [10].

'The tissue-engineering sector is currently emerging as a multid isc ip linary field, demanding the integration of the life sciences, chemistry, eng ineering, clinic a I medicine and commerce, which in time is likely to have a major commercial impact.'

Undoubtedly tissue-engineered products could benefit a large number of patients. In pivotal clinical trials of the first tissue-engineered product, Apligraf (skin) admirably demonstrated its benefit over traditional treatment in terms of the number of leg ulcers healed, speed of healing and reduced rate of recurrence [11]. However none of the tissue-engineered products to date have demonstrated the substantial cost benefits a new clinical product requires if it is to universally displace current therapy and best practice [12]. A European Commission report in 2003 noted that, 'T he comparison of treatment costs alone is not sufficient, as different treatments can result in different outcomes. The effectiveness of treatments needs to be included in the comparison'. H owever even taking these wider cost implications into account, the current data on tissueengineered products does not provide clear economic evidence of their superiority [13]. This shortfall is mainly due to the high cost of manufacture associated with low volume production
For example, O rganogenesis, in the period leading to its financial crisis in late 2002, reported in its Annual Report, '... C ost of product sales continues to exceed product sales due to the high costs associated with low volume production...' [14]. This was a commercially unsustainable situation and 7 months later the company filed under Chapter 11 .

Today's increasing emphasis placed on cost containment by healthcare providers is an important issue. W ithout efficient scal able translation techniques, the resulting high cost of tissue-engineering products will effectively limit their market despite the potentially overwhelming benefits to both the patient and society. In addition, aside from the issue of tissue-engineered products being expensive to produce, it is also no use only being able to make a few tissues at a time when the potential demand is orders of magnitude larger [15].

Presently, tissue engineers are almost exclusively focused on using laboratory-based techniques rather than economic 'mass production' [16]. This critical issue is amongst those highlighted by many commentators when discussing the industries poor performance to date including $M$ ichael Lysaght and Anne $H$ azlehurst (Brown U niversity, U SA): "Although scientifically strong, the companies lacked the skill sets required to develop low-cost manufacturing procedures" [4]. Linda Griffith (M assachusetts Institute of Technology, U SA) together with Gail $N$ aughton the former President and cofounder of Advanced Tissue Sciences, also suggested that, "There are still many technical challenges to overcome before we create 'off-the-shelf' tissues that represent the translation of scientific discoveries into treatments for millions of patients. The successful large-scale production of engineered tissues requires an adequate source of healthy expandable cells, the optimisation of scaffolds, and the creation of bioreactors, which mimic the environment of the body and that are amenable to scale-up" [17]. These same issues were highlighted by the $\mathrm{N}$ ational Institutes of $\mathrm{H}$ ealth Bioengineering Consortium when discussing the potential for 'off-the-shelf' products: 'For tissue engineering to meet the true clinical demands, the products must be manufactured reproducibly, in large numbers, and be available on demand...Scalable manufacturing processes permit many units to be made in a unified manner, and allow diseases that affect large patient populations to be addressed in an efficient and costeffective way' [18]. Similar sentiments have been 
offered by other industry experts including Tony Ratcliffe (whilst at Advanced Tissue Sciences) and Laura N iklason (D uke U niversity, USA) [19].

There are several ways in which cost can be reduced and consistency increased. 0 ne is to use individual disposable multi-tasking bioreactors and associated support systems with a design that is simple enough to be mass produced. Thus the bioreactor carries out all the appropriate steps e.g., cell expansion, scaffold seeding and construct maturation whilst being an integral part of the delivery container [20]. Keeping the tissue-engineered organ in the same chamber from initial 'creation' to just prior to implantation by the surgeon has bioengineering advantages for example, no manual intervention is required and therefore reduced chance of fatigueinduced errors. It also has major cost benefits such as ease of automation. Automation would allow cost-effective operation including minimizing the requirement for specialist technical support, reducing waste and increasing output and profitability whilst satisfying the general desire by clinicians to provide a high level of quality assurance to their patients [21]. Few designs for full automation are yet developed, although Millenium Biologix (Kingston, Ontario, Canada) is testing a turn-key engineered cartilage system [22]. Several research centers and at least one company (Sciperio Inc, O klahoma C ity, USA) are exploring other alternatives including the use of adaptations of matrix printers to lay down human cells and bonding agent in a precise 3D shape, described as organ printing. Using this methodology, cell printing is automated and fully computer controlled, thus potentially capable of the highspeed fabrication of tissues [23]. This platform technology is broadly based on personal computers that are bespoke programmed to drive highly modified inkjet type printers, plotters or 'cell dispensers'. The 'bioinks' are cells and biodegradable gels [24]. O verall, tissue-engineering companies are tending to go forward in a very pragmatic manner, for example automating one step of the process at a time. Thus, the pieces of the jigsaw for automation are genuinely beginning to emerge, albeit at a very early stage in development.

Since the demise of the pioneering tissue engineering companies, there has been a slow but growing realization in the industry that the manufacturing process lies at the heart of a successful product. All the major international players including Intercytex plc (C ambridge, UK ) and the rejuvenated $\mathrm{O}$ rganogenesis, have a high degree of commitment to future automation. An excellent example is O rganogenesis who are currently automating the fluid handling part of their process of manufacture for their lead product Apligraf. The modification is described in detail in their recent patent: 'The system of the present invention allows for more convenient automation to insert and remove biological materials from the ports in the lid (of the bioreactor) without requiring that the lid be removed, and without requiring significant labor, unlike typical current processes. In an automated system, bioreactors could be transported on a conveyor or with mechanical handling equipment that can move the bioreactors from one location to another. Using robotics or with $x-y-z$ movement machines, syringes or other nozzles can be moved into and out of the bioreactor to insert or remove material. Such accessibility can reduce risks of contamination and make the system less labor intensive and more amenable to automation' [101].

'The bottom line is that commercial tissue eng ineering is no different from a ny other technology-based business and therefore in order to succeed must deliver profitable products with clear cost benefits.'

For tissue engineering, the fabrication process and the product are in fact inseparable, a stark contrast to both chemical pharmaceuticals and medical devices. Even for more complex biopharmaceuticals with their high gross profits, manufacturing productivity is no longer considered as an afterthought. Therefore to fulfil its promise, the tissue-engineering industry with its high upfront $R \& D$ costs must improve on its current low profit margins by integrating production strategy into every aspect of the product. The bottom line is that commercial tissue-engineering is no different from any other technology-based business and therefore in order to succeed must deliver profitable products with clear cost benefits.

\section{Acknowledgement}

At the time of writing this editorial, the future of $D$ ermagraft looks uncertain followed the planned exit by Smith \& $N$ ephew from D ermagraft and its related products. 


\section{Bibliography}

1. N ational Diabetes Statistics. $\mathrm{N}$ ational Diabetes Information Clearinghouse (N DIC). 25 September 2003. http://diabetes.niddk.nih.gov/dm/pubs/stati stics/index.htm.

2. European Commission 2001. O pinion on the State of the Art Concerning Tissue Engineering D oc.SAN C O/SCM PM D /2001/0006 Final (2001).

3. Lysaght M J, Reyes J: The growth of tissue engineering. Tissue Engineering 7, 485-493 (2001).

4. Lysaght M J, H azelhurst AL: Tissue engineering: the end of the beginning. Tissue Engineering 10, 309-320 (2004).

5. Lysaght M J, N guy N A, Sullivan K: An economic survey of the emerging tissue engineering industry. Tissue Engineering 4, 231-238 (1998).

6. Bromley A: Tissue engineering technologies and markets. Clinica Report (2001).

7. Bromley A: Tissue engineering - Ready for mass production? Clinica $M$ arket Briefing (2003).

8. Lysaght M J: 'T he tissue engineering enterprise' K eynote Presentation. International Conference on Engineering Tissue Growth, Pittsburgh, PA, USA, 26-29 $M$ arch 2003.

9. Kemp PD : Tissue Engineering Sector $N$ etworking M eeting - D epartment of Trade and Industry, N ovember 2003.
10. Archer R, W illiams DJ: Why tissue engineering needs process engineering $\mathrm{N}$ at. Biotechnol. 23, 1353-1355 (2005).

11. Falanga $V, M$ argolis D J, Alvaraez $O$, Auletta $M, M$ aggiacomo $F$, Altman $M$, Jensen J, and the Graftskin Investigators Group: Rapid healing of venous ulcers and lack of clinical rejection with an allogeneic cultured human skin equivalent. Arch. D ermatol. 134, 293-300 (1998).

12. Redekop WK, M cD onnell J, Verboom P, Lovas K, Kalo Z: The cost effectiveness of Apligraf treatment of diabetic foot ulcers. Pharmacoeconomics 21, 1171-1183 (2003).

13. European Commission Report 2003, H uman tissue-engineered products- Today's markets and future prospects. Report EU R 21000 EN (2003).

14. O rganogenesis Inc, Annual Company Report. United States Securities and Exchange Commission, Form 10K, 23rd April 2002

15. $\mathrm{M}$ ason $\mathrm{C}$ : Automated tissue engineering: a major paradigm shift in healthcare. M edical D evice Technology 14(1), 16-18 (2003).

16. M ason C: T issue Engineering. Biotechnology Investment Today 2, 20-27 (2003).

17. Griffith $L G, N$ aughton $G$ : Tissue engineering-current challenges and expanding opportunities. Science 295 , 1009-1016 (2002).

18. N ational Institutes of $\mathrm{H}$ ealth Bioengineering Consortium 2001. Reparative medicine: Growing tissues and organs (2001).
19. Ratcliffe A. Niklason LE: Bioreactors and bioprocessing for tissue engineering. Ann. N Y Acad. Sci. 961, 210-205 (2002).

20. $M$ artin $I$, Wendt $D, H$ eberer $M:$ The role of bioreactors in tissue engineering. Trends Biotechnol. 22, 80-86 (2004)

21. Armstrong RD, 0 gier WC, M aluta J: Clinical systems for the production of human cells and tissues. Biotechnology (N Y) 13, 449-453 (1995).

22. M illenium Biologix press release: M illenium Biologix provides update on corporate strategy, progresses with continued business and financial restructuring and appoints Brian Fielding as interim CEO Kingston. $M$ arch 29 (2006)

23. Jakab K, N eagu A, M ironov V, Forgacs G: $O$ rgan printing: fiction or science Biorheology 41(3-4), 371-375 (2004).

24. Jakab K, N eagu A, M ironov V, M arkwald $R R$, Forgacs $G$ : Engineering biological structures of prescribed shape using selfassembling multicellular systems. Proc. $\mathrm{N}$ atl Acad. Sci. U SA 101(9), 2864-2869 (2004).

Patent

101. RoosE, O 'Reilly C, Chevere R, W ilkins LM : Culture dish and bioreactor system. US Patent $6,730,510$, M ay 4 (2004). 